\title{
ПРИМЕНЕНИЕ СПЕКТРОСКОПИИ ВЫЖИГАНИЯ ПРОВАЛОВ ДЛЯ ИССЛЕДОВАНИЯ ПЕРВИЧНЫХ ПРОЦЕССОВ ФОТОСИНТЕЗА
}

Әффект выжигания провалов в неоднородно уширенных спектрах поглощения под действием монохроматического облучения при гелиевых температурах $\left[{ }^{1,2}\right]$, связанный с селективным фотопревращением поглощающих центров, позволяет определять однородные ширины оптических переходов. Одним из основных его применений является исследование времен молекулярных релаксаций $\left[{ }^{3,4}\right]$. В настоящей работе методом выжигания провалов изучаются релаксации, связанные с первичными процессами преобразования энергии в фотосинтетических реакционных центрах (РЦ). Возможность его применения в данном случае обусловлена тем, что процесс первичного разделения зарядов как в фотосистеме I (ФС I), так и в фотосистеме II (ФС II) может осуществляться при сколь угодно низких температурах, причем необратимо. Первая попытка такого рода была сделана в $\left[{ }^{5}\right]$, где исследовались спектральные изменения при монохроматическом облучении суспензии клеток хлореллы при 4,2 К в области поглощения первичного донора электрона в РЦ ФС I (Р700). Был обнаружен провал, ширина которого соответствует времени релаксации не менее $12 n c$, и приведен ряд фактов и соображений, косвенно свидетельствующих в пользу того, что этот провал обусловлен фотопревращением Р700 в результате поглог щения света именно этими центрами, а не антенным хлорофиллом. Однако низкое относительное содержание РЦ ФС I затрудняло наблюдение провалов и интерпретацию результатов, отчего все дальнейшие эксперименты выполнялись на специально подобранных мутантных штаммах хламидомонады с естественным обогащением РЦ ФС I или РЦ ФС II. Они были предоставлены нам сотрудниками БиНИИ ЛГУ А. С. Чунаевым и В. В. Тугариновым.

Первичные процессы в ФС I исследовали на штамме 516-3a, у которого отношение хлорофилл $а / \mathrm{P} 700$ составляет около 25 , т. е. в 20 раз превышает относительное содержание В700 в диком типе [ $\left.{ }^{6}\right]$. Мы обнаружили два различающихся по ширине и форме типа провалов: один в области 695-702 нм (рис. 1,a) и другой - в области 686-696 нм (рис. 1,6$)$. Чтобы получить представление о спектрах поглощения центров, ответственных за образование провалов, были исследованы зависимости максимальной (насыщенной) глубины провалов от длины волны выжигания («спектры выжигаемости»). Положение максимума $(698$ нм) и форма «спектра выжигаемости» провалов первого типа (рис. 1,8$)$ указывают на то, что за. выжигание ответственно фотопревращение Р700. По ширине провала обнаружено, что время жизни возбужденного состояния в данном случае превышает 50 nc. Форма и «спектр выжигаемости» провалов второго типа (рис. 1,б,2) свидетельствуют о том, что они обусловлены коротковолновым электрохромным сдвигом энергетического перехода другого компонента РЦ ФС I, имеющего максимум поглощения у 693 нм. Этот компонент, вероятно, тож- 

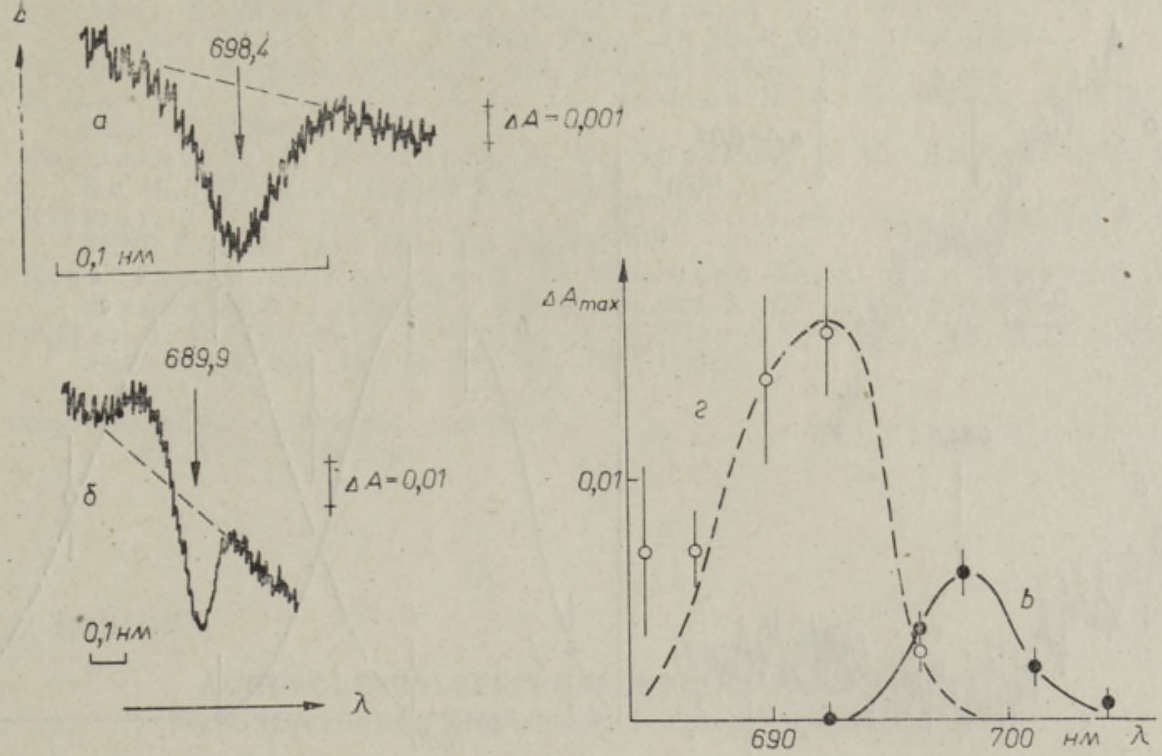

Рис. 1. Фрагменты спектров суспензий клеток Chlamydomonas reinhardii 516-3а при $4,2 \mathrm{~K}$ после 8 мин облучения светом 698,4 нм (a) и после 20 мин облучения светом $689,9 \mathrm{\mu м}($ б); зависимости максимальной глубины провалов первого $(в)$ и второго (2) типов от длины волны облучения. Полуширина (гауссова) аппаратной функции при выжигании и регистрации - 0,2 н.м. Оптическая плотность на длине волны 673 нм составляла $2,1(a$, б) и $1,0(\varepsilon, 2)$.

дествен обнаруженному в [7] димеру (или, возможно, мономеру) хлорофилла $а$ с максимумом 695 нм, предположительно, функционирующему как первичный акцептор электрона в РЦ ФС I. Время релаксации возбужденного состояния данного компонента, полученное из ширины провала, составляет $8,6 \pm 0,5$ nc. Әта величина, в предположении, что она определяется скоростью переноса энергии от рассматриваемого компонента РЦ на Р700, дает расстояние между ними около $20 \AA$.

Первичные процессы в ФС II изучали на штаммах $420 / 7$ и N-154 У первого из них отношение хлорофилл $а / \mathrm{P} 680$ составляет $50-70$, у второго - около 200. Для образцов мутанта 420/7 с добавкой феррицианида наблюдали провалы двух типов: первый - в области 678682 нм (рис. 2,a), а второй - в области 682-688 нм (рис. 2,б). «Спектры выжигаемости» показали, что за провалы первого типа (рис. 2,в) ответственны центры P680, претерпевающие в результате переноса электрона длинноволновый электрохромный сдвиг, а провалы второго типа (рис. 2,2) обязаны, скорее всего, молекуле феофитина, входящей в состав РЦ ФС II и обычно функционирующей как первичный акцептор электрона $\left[{ }^{8}\right]$. В последнем случае элементарные акты при выжигании провала осуществляются, вероятно, в необычной последовательности: роль первичного донора электрона играет фотовозбужденная молекула феофитина, после чего происходит темновой перенос электрона от Р680 на катион-радикал феофитина, а затем, как обычно, - от вторичного донора на катион-радикал Р680. Образование провала здесь может быть обусловлено электрохромным сдвигом перехода молекулы феофитина. Определенные по ширинам провалов времена релаксаций возбужденных состояний составили $3,8 \pm 0,8$ nc для P680 и $9,8 \pm 1,5$ nс для феофитина. На образцах штамма $420 / 7$ с добавками дитионита наблюдались провалы, соответствующие только Р680. Отсутствие достоверных провалов в области поглощения феофитина обусловлено, по-видимому, тем, что в данных условиях вторичный акцептор 


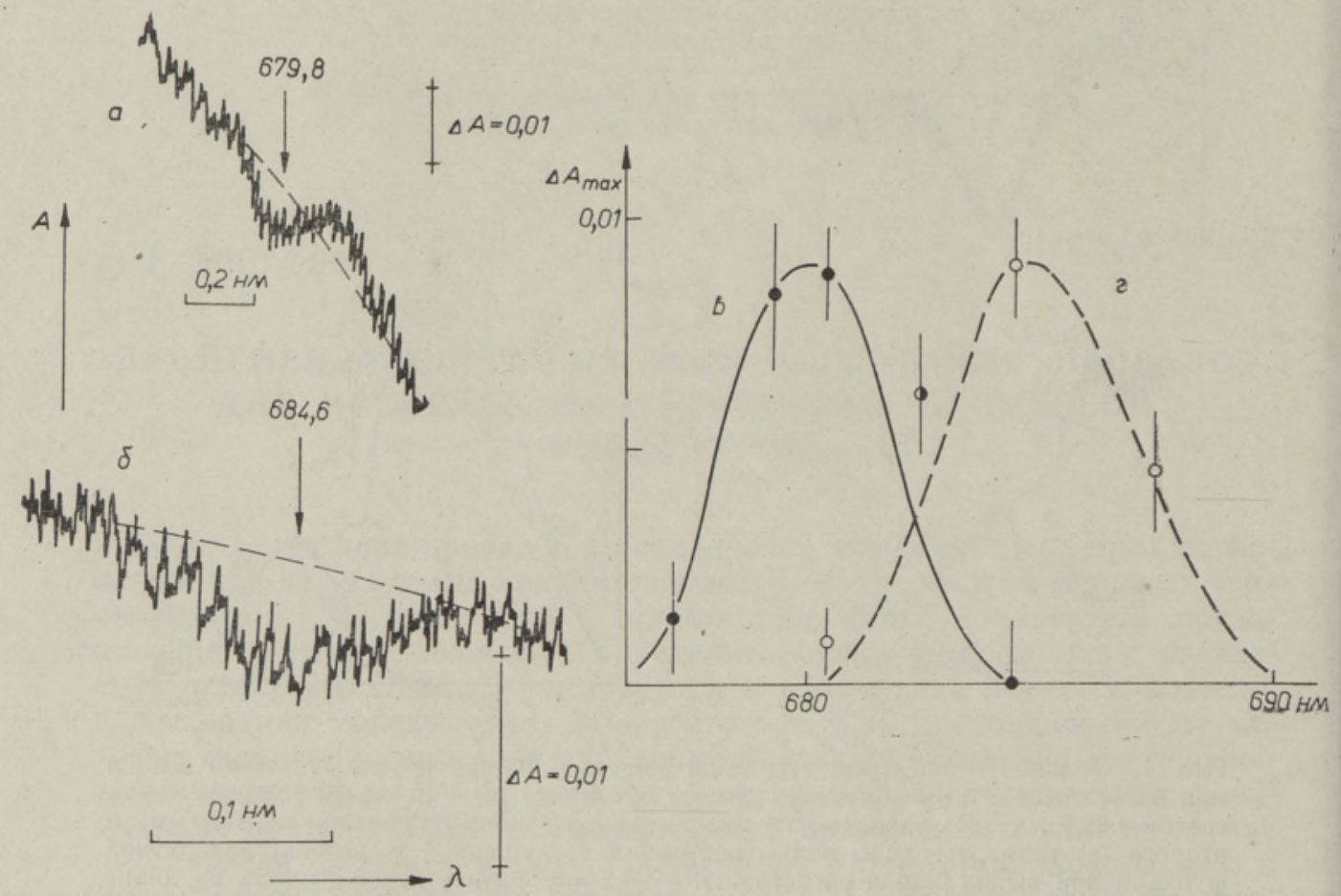

Рис. 2. Фрагменты спектров суспензий клеток Chlamydomonas reinhardii $420 / 7$ при $4,2 \mathrm{~K}$ в присутствии $50 \mathrm{mM}$ феррицианида после 40 мин облучения светом 679,8 нм (a) и 684,6 нм (б); зависимости максимальной глубины провалов обоих типов $(8$, г) от длины волны облучения. Полуширина аппаратной функции при выжигании и регистрации - 0,036 нм. Оптическая плотность на длине волны 672 нм составляла 1,1 .

электрона $(Q)$ восстановлен и перенос электрона от феофитина на него невозможен.

Мутантный штамм N-154, судя по исследованным нами дифференциальным спектрам, не имеет молекулы феофитина в составе РЦ ФС II. У этого штамма наблюдалось выжигание провалов только одного типа и только в присутствии феррицианида. Исследование «спектра выжигаемости» показало, что провалы в данном случае обязаны центрам Р680. Время релаксаций возбужденного состояния последних, определенное по ширине провала, составило при этом $10 \pm 2 \mathrm{nc}$.

Полученные результаты свидетельствуют о том, что времена релаксаций возбужденных состояний первичных доноров электрона ФС I и ФС II существенно различаются между собой. В этом, по-видимому, прөявляются различия в скоростях первичного переноса электрона в этих фотосистемах. К бактериальным РЦ, у которых время первичного фотопереноса электрона составляет единицы пикосекунд [9 $]$, оказываются ближе РЦ ФС II, а не РЦ ФС I. Аналогия между РЦ ФС II и бактериальными РЦ в организации системы акцепторов электрона уже отмечалась в $\left[{ }^{10}\right]$.

\section{ЛИТЕРАТУРА}

1. Гороховский А. А., Ка арли Р. К., Ребане Л. А., Письма в ЖЭТФ, 20, вып. 7, $474-479$ (1974).

2. Kharlamov, B. M., Personov, R. I., Bykovskaya, L. A., Opt. commun., 12, № $2,191-193$ (1974).

3. De Vries, H., Wiersma, D. A., Phys. Rev. Lett., 36, № 2, 91-94 (1976). 
4. Voelker, S., Macfarlane, R. M., Genack, A. Z., Trommsdorff, H. P., van der W a a l s, J. H., J. Chem. Phys., 67, № 4, 1789-1765 (1977).

5. М а слов В. Г., Докл. АН СССР, 246, № 6, 1511-1513 (1979),

6. Маслов В. Г., Чуна ев А. С., Т угаринов В. В., Биофизика, 25 , вып. 5 , 925-927 (1980).

7. Shuvalov, V. A., Klevanik, A. V., Sharkov, A. V., Kryukov, P. G., K e, B., FEBS Lett., 107, № 2, 313-316 (1979).

8. Klimov, V. V., Klevanik, A. V., Shuvalov, V. A., Krasnovsky, A. A., FEBS Lett., 82, № 2, 183-186 (1977).

9. Клеваник А. В., Кр юков П. Г., Матвеец Ю. А., Семиишен В. А., Ш у в а ло в В. А., Письма в ЖЭТФ, 32, вып. 2, 107-111 (1980).

10. Fa jer, J., D a vis, M. S., F orman, A., K 1 i mov, V. V., Dola n, E., Ke, B., J. Amer. Chem. Soc., 102, № 23, 7143-7145 (1980).

Государственный оптический институт им. С. Н. Вавилова

\section{G. MASLOV}

\section{AUGUPÕLETUSSPEKTROSKOOPIA RAKENDAMINE FOTOSONTEESI PRIMAARPROTSESSIDE UURIMISEKS}

Chlamydomonas reinhardii mutanttüvede reaktsioonitsentrite fotosüsteemide (FS) I ja II primaarsete fotoprotsesside uurimiseks on rakendatud augu põletamist neeldumisspektritesse vedela heeliumi temperatuuril. Identifitseerimaks reaktsioonitsentrite komponente, mis põhjustavad augu teket, määrati augu maksimaalse sügavuse sōltuvus lainepikkusest. FS I-s johtus augu teke P700 fotooksüdeerumisest ning reaktsioonitsentri komponendi (neeldumismaksimum $693 \mathrm{~nm}$ ) elektrokromaatilisest nihkest. FS II-s leiti augupōletuse mehhanismid olevat seotud P680 ja feofütiini fotomuundumisega. Aukude laiusest on arvutatud vastavad ergastusolekute relaksatsiooniajad.

\section{G. MASLOV}

\section{APPLICATION OF HOLE-BURNING SPECTROSCOPY TO THE STUDY OF PRIMARY PROCESSES OF THE PHOTOSYNTHESIS}

A hole-burning in absorption spectra at helium temperatures has been used for the study of primary photoprocesses in the reaction centers (RC) of photosystems I and II (PS I and PS II) of Chlamydomonas reinhardii mutant strains. In order to identify the RC components responsible for burning, the maximal hole depth as a function of the burning wavelength has been studied. In studies of PS I a hole has been detected evidently caused by the photooxidation of P700. The relaxation time of P700* evaluated from the hole width is longer than 50 ps. Another hole has been detected, for which the electrochromic shift of the RC component with its absorption maximum at $693 \mathrm{~nm}$ ca be held responsible. In studies of PS II a hole has been observed corresponding to the photoreaction of P680 (the excited state relaxation time being $3.8 \mathrm{ps}$ ). In the spectral region of $682-688 \mathrm{~nm}$ another hole has been found, which is tentatively related to the photoreaction of pheophytin (primary electron acceptor in RC PS II) as a result of its own light absorption. The excited state relaxation time of pheophytin derived from the hole width is $9.8 \mathrm{ps}$. 